\title{
Dermatomal Somatosensory Evoked Potentials And Cortical Somatosensory Evoked Potentials Assessment In Congenital Scoliosis
}

\section{Zhenxing Zhang}

Department of Orthopaedics, Xi'an HongHui Hospital, Xi'an Jiaotong University, Xi'an, Shaanxi

\section{Yi Wang}

Department of Orthopedics, Zhongnan Hospital of Wuhan University, Wuhan, Hubei

\section{Tao Luo}

Department of Orthopedics, Zhongnan Hospital of Wuhan University, Wuhan, Hubei

\section{Yang Yuan}

Department of Functional Examinantion , Xi'an HongHui Hospital, Xi'an Jiaotong University, Xi'an, Shaanxi

\section{Jingfeng Li ( $\nabla$ jingfengli@whu.edu.cn )}

Department of Orthopedics, Zhongnan Hospital of Wuhan University, Wuhan, Hubei

\section{Research Article}

Keywords: Congenital scoliosis, Dermatomal somatosensory evoked potentials (DSEPs), Cortical somatosensory evoked potentials (SSEPs), Sensitivity

Posted Date: July 20th, 2021

DOl: https://doi.org/10.21203/rs.3.rs-647962/v1

License: (9) This work is licensed under a Creative Commons Attribution 4.0 International License. Read Full License

Version of Record: A version of this preprint was published at BMC Neurology on February 15th, 2022. See the published version at https://doi.org/10.1186/s12883-022-02579-4. 


\section{Abstract}

Background: The aim of this study was to assess the value of dermatomal somatosensory evoked potentials (DSEPs) and cortical somatosensory evoked potentials (SSEPs) in monitoring spinal cord function for patients with congenital scoliosis (CS).

Methods: This study retrospectively analyzed the neurophysiological signals recorded in 62 patients from our orthopedic department who underwent MRI, CT and a specialist physical examination by a surgeon to confirm the diagnosis of CS. To observe the incidence of abnormal DSEPs and SSEPs in CS patients and to analyze the difference in sensitivity and reliability between the two in the examination of scoliosis patients.

Results: All patients were evaluated with total spine magnetic resonance imaging (MRI). Only 23 patients (37.09\%) showed intradural lesions in the MRI findings. Abnormal waveforms were observed in the DSEPs of 60 patients $(96.8 \%), 25$ of which $(40.3 \%)$ had abnormal waveforms in the tibial SSEPs, and the difference was statistically significant (P凶0.05). Of the 10 patients with clinical symptoms, $2(20 \%)$ had abnormal tibial SSEPs waveforms, and $23(44.2 \%)$ of 52 patients without clinical symptoms had abnormal tibial SSEPs waveforms. DSEPs are more sensitive to microscopic posterior column dysfunction in patients with CS that cannot be detected by either imaging or routine clinical examination.

Conclusion: DSEPs provide evidence for the type of neurophysiological dysfunction in patients with congenital scoliosis. Preoperative DSEPs assessment is recommended as a baseline examination for intraoperative monitoring and comparison with the postoperative situation. DSEPs recording complements the information obtained from routine clinical and radiological evaluation.

\section{Background}

Spinal deformities are caused by the formation of abnormal vertebrae. Hemivertebrae, loss of vertebrae or intervertebral union can cause asymmetric growth, resulting in secondary deformities ${ }^{[1]}$. Patients with congenital scoliosis often have a combination of spinal cord developmental malformations (including spinal cord embolism, spinal cord longitudinal fracture, and spinal cord cavity), the incidence of which has been reported to vary widely $(18 \%-58 \%)^{[2,3]}$. Spinal cord deformities are more insidious than spinal deformities. It is difficult to detect clinically on physical examination and X-ray, and often requires Magnetic resonance imaging(MRI) and three-dimensional CT (3D CT). MRI can show the morphological abnormalities of spinal cord malformations, and 3D CT can clearly show the vertebral bodies with developmental malformations, but both of them lack the evaluation of spinal cord nerve function ${ }^{[4]}$.

Somatosensory evoked potentials (SEP) are thought to reflect some of the functional conduction of the spinal cord and have been widely used in clinical practice for early detection of preoperative neurological impairment in patients with scoliosis, clinical assessment of spinal cord disease, intervention and intraoperative monitoring of spinal surgery. Also, when conventional clinical examinations and imaging 
such as MRI are not completely conclusive, they can complement the diagnostic process ${ }^{[5]}$. There have been few studies in clinical use of SEPs for identifying spinal cord function in patients with CS. The purpose of this study was to assess the differences in the role of DSEPs and SSEPs in the assessment of spinal cord function in patients with CS. The difference in sensitivity between DSEPs and SSEPs was also analyzed.

\section{Methods}

A total of 62 patients were admitted to the Neurospinal Department of our hospital from May 2009 to March 2020. There were 28 males and 34 females, with an average age of 15.9 years (range 6-40 years). Through X-ray evaluation of scoliosis, the mean Cobb angle was $60.2^{\circ}\left(\right.$ range $\left.41^{\circ}-92^{\circ}\right)$ in 54 cases of scoliosis and $58^{\circ}$ in 8 cases of kyphosis. Among them, 23 cases of scoliosis patients were complicated with congenital spinal cord malformations (including tethered cord, diastematomyelia, syringomyelia, etc.). This research project was approved by the Biomedical research ethics committee of Hong Hui Hospital, Xi'an Jiaotong University.

The DSEPs and SSEPs of the relevant muscles were conducted using a Nihon Kohden electromyography device (DANTEC MEB-9404C, Nihon Kohden, Japan). Complete the DSEPs and SSEPs examination by referring to the relevant technical details reported by Slimp ${ }^{[11]}$. All patients were examined preoperatively in a shielded room at $22-28^{\circ} \mathrm{C}$. A somatosensory evoked potential procedure was used, with surface electrode stimulation at 2-3 times the sensory threshold and a stimulation frequency of $3 \mathrm{~Hz}$, and the signal was superimposed an average of 100 times and repeated 2 times. The stimulation sites and recording sites for DSEPs and SSEPs are shown in Table 1a and Table 1b, respectively. All electrophysiological recordings were quality controlled and assessed by the same authors (YY).

Table 1

a SSEPs stimulation and recording site

\begin{tabular}{|lll|}
\hline $\begin{array}{l}\text { Represents nerve } \\
\text { roots }\end{array}$ & Stimulation site & $\begin{array}{l}\text { Recording site } \\
\text { International EEG 10-20 System Electrode } \\
\text { Placement Method }\end{array}$ \\
\hline $\mathrm{C} 6-\mathrm{T} 1$ & Median nerve of the wrist & $\mathrm{C}^{\prime} \mathrm{C} 4^{\prime}-\mathrm{Fz}$ \\
\hline $\mathrm{C} 8-\mathrm{T} 1$ & Ulnar nerve of the wrist & $\mathrm{C}^{\prime} \mathrm{C} 4^{\prime}-\mathrm{Fz}$ \\
\hline $\mathrm{L} 4-\mathrm{S} 2$ & $\begin{array}{l}\text { Tibial nerve of the medial } \\
\text { ankle }\end{array}$ & $\mathrm{Cz}^{\prime}-\mathrm{Fz}$ \\
\hline
\end{tabular}


Table 1

b DSEPs stimulation and recording site

\begin{tabular}{|c|c|c|}
\hline $\begin{array}{l}\text { Represents } \\
\text { nerve roots }\end{array}$ & Stimulation site & $\begin{array}{l}\text { Recording site } \\
\text { International EEG 10-20 System Electrode } \\
\text { Placement Method }\end{array}$ \\
\hline C5 & $5 \mathrm{~cm}$ below the shoulder peak & $\mathrm{C}^{\prime} \mathrm{C} 4^{\prime}-\mathrm{Fz}$ \\
\hline C6 & Thumb & $\mathrm{C}^{\prime} \mathrm{C} 4^{\prime}-\mathrm{Fz}$ \\
\hline $\mathrm{C7}$ & Middle finger & $\mathrm{C}^{\prime} \mathrm{C} 4^{\prime}-\mathrm{Fz}$ \\
\hline C8 & Little finger & $\mathrm{C}^{\prime} \mathrm{C} 4^{\prime}-\mathrm{Fz}$ \\
\hline $\mathrm{T} 2$ & $\begin{array}{l}\text { Chest and arm line flat axillary } \\
\text { crease }\end{array}$ & $\mathrm{Cz}-\mathrm{Fz}$ \\
\hline $\mathrm{T} 4$ & Flat nipple, mid-axillary line & $\mathrm{Cz}-\mathrm{Fz}$ \\
\hline T6 & Flat glabella, mid-axillary line & $\mathrm{Cz}-\mathrm{Fz}$ \\
\hline T8 & $\begin{array}{l}\text { Midpoint between T6 and T10, } \\
\text { mid-axillary line }\end{array}$ & $\mathrm{Cz}-\mathrm{Fz}$ \\
\hline T10 & Flat umbilicus, mid-axillary line & $\mathrm{Cz}-\mathrm{Fz}$ \\
\hline T12 & Flat iliac crest, midaxillary line & $\mathrm{Cz}-\mathrm{Fz}$ \\
\hline L2 & Midpoint of the groin & $\mathrm{Cz}-\mathrm{Fz}$ \\
\hline L3 & $\begin{array}{l}15 \mathrm{~cm} \text { below anterior superior iliac } \\
\text { spine }\end{array}$ & $\mathrm{Cz}-\mathrm{Fz}$ \\
\hline L4 & $\begin{array}{l}6 \mathrm{~cm} \text { medially below the inferior } \\
\text { patellar rim }\end{array}$ & $\mathrm{Cz}-\mathrm{Fz}$ \\
\hline L5 & $\begin{array}{l}\text { Medial aspect of the I } \\
\text { metatarsophalangeal joint }\end{array}$ & $\mathrm{Cz}-\mathrm{Fz}$ \\
\hline S1 & $\begin{array}{l}\text { lateral aspect of the } \mathrm{V} \\
\text { metatarsophalangeal joint }\end{array}$ & $\mathrm{Cz}-\mathrm{Fz}$ \\
\hline
\end{tabular}

Sixty normal subjects in our laboratory were used to obtain normal values as a control group. All subjects showed no clinically detectable neurologic deficit, nor had history of trauma or surgery to the brain, spine, or lower extremities. The judgment criteria of DSEPs and SSEPs are mainly to analyze the latency, interpeak latency, amplitude and the degree of waveform differentiation, and compare them. The waveforms of normal people are stable and basically similar, and the waveforms in lesions are poorly differentiated or even disappear. The latency (PL) of each wave, the latency difference (ILD) of bilateral P1 wave and the difference of bilateral amplitude (AMP) were measured. Judgment of abnormal results: $\llbracket$ Absolute latency $>+2 S$, खinter-lateral latency difference $>2 \mathrm{~ms}$; खinter-lateral amplitude difference $\geq 50 \%$; \poor waveform differentiation or waveform disappearance ${ }^{[11-13]}$. SPSS19.0 statistical software 
package was used to analyze the data, and $\chi^{2}$ test and correlation analysis were used to indicate that the difference was statistically significant, $p<0.05$.

\section{Results}

The classification of abnormal DSEPs and SSEPs waveforms in 62 patients is shown in Table 2. Among the indicators of waveform abnormality classification, the highest positive rate was found for prolonged latency and latent interlateral difference.

Table 2

Classification of pathological changes in DSEPs and CSEPS

\begin{tabular}{|c|c|c|c|c|}
\hline & $\begin{array}{l}\text { Waveform } \\
\text { vanishing (n) }\end{array}$ & $\begin{array}{l}\text { Prolonged wave } \\
\text { latency ( } n)\end{array}$ & $\begin{array}{l}\text { Asymmetry in latency of left and } \\
\text { right lateral waves(n) }\end{array}$ & $\begin{array}{l}50 \% \text { difference } \\
\text { in volatility }\end{array}$ \\
\hline DSEPS & 20 & 52 & 13 & 2 \\
\hline SSEPS & 0 & 22 & 24 & 5 \\
\hline
\end{tabular}

Of the 62 patients included, 10 presented with neurological symptoms by routine clinical examination(Table 3 ) and 23 had intravertebral lesions suggested by MRI imaging(Table 4). The incidence of abnormal DSEPs and SSEPs was $96.8 \%$ and $40.3 \%$, respectively. Significant differences were found between the two groups. In 10 patients with neurologic symptoms, 2 had abnormal waveforms of SSEPs (Tibial nerve). In other 52 patients without neurologic symptoms, 23 had abnormal waveforms of SSEPs. The incidence of abnormal DSEPs and SSEPs with and without neurological symptoms was $100 \%$ vs $20 \%$ and $96.2 \%$ vs $44.2 \%$, respectively, with statistically significant differences at $P<0.05$. The specific results are shown in Table 3 .

Table 3

Analysis on abnormality rate of DSEPs and CSEPS

\begin{tabular}{|c|c|c|c|c|c|}
\hline \multirow{2}{*}{$\begin{array}{l}\text { Neurologic } \\
\text { symptoms }\end{array}$} & \multicolumn{2}{|l|}{ DSEPs } & \multicolumn{2}{|l|}{ SSEPS } & \multirow[t]{2}{*}{$p$ Value } \\
\hline & $\begin{array}{l}\text { Cases } \\
(n=62)\end{array}$ & $\begin{array}{l}\text { Abnormality } \\
\text { rate }\end{array}$ & $\begin{array}{l}\text { Cases } \\
(n=62)\end{array}$ & $\begin{array}{l}\text { Abnormality } \\
\text { rate }\end{array}$ & \\
\hline With & 10 & $100 \%$ & 2 & $20 \%$ & $\square 0.05$ \\
\hline Without & 50 & $96.2 \%$ & 23 & $44.2 \%$ & $\square 0.05$ \\
\hline $\begin{array}{l}\text { Total abnormality } \\
\text { waveforms }\end{array}$ & 60 & $96.8 \%$ & 25 & $40.3 \%$ & $\square 0.05$ \\
\hline
\end{tabular}


Table 4

Comparison of dermatomes in DSEPs

\begin{tabular}{|c|c|c|c|c|c|c|c|}
\hline \multirow{2}{*}{$\begin{array}{l}\text { Intraspinal } \\
\text { pathologies }\end{array}$} & \multicolumn{2}{|l|}{ MRI } & \multicolumn{4}{|c|}{ dermatomes of DSEPs } & \multirow{2}{*}{$\begin{array}{l}p \\
\text { Value }\end{array}$} \\
\hline & $\begin{array}{l}\text { Case } \\
(\mathrm{n}= \\
62)\end{array}$ & $\begin{array}{l}\text { Abnormality } \\
\text { rate }\end{array}$ & Normal & Abnormal & Total & $\begin{array}{l}\text { Abnormality } \\
\text { rate }\end{array}$ & \\
\hline with & 23 & $37.1 \%$ & 39 & 153 & 192 & $79.6 \%$ & $<0.05$ \\
\hline without & 39 & & 124 & 171 & 295 & $57.9 \%$ & \\
\hline$p$ Value & & & & & & $<0.05$ & \\
\hline
\end{tabular}

Comparison of dermatome in DSEPs between patients with intraspinal pathologies and without intraspinal pathologies, the ratio of abnormal dermatomes in patients with intraspinal malformations was $79.6 \%$, while it was $57.9 \%$ in patients without intraspinal malformations. In congenital spinal malformations, the occurrence rate of abnormal segments of DSEPs in patients with spinal cord dysplasia (such as tethered cord, diastematomyelia, syringomyelia, etc.) was higher than that in patients without spinal cord malformation. The abnormality rate in both groups was statistically significant, $P<$ 0.05. The statistical results are shown in Table 4.

\section{Discussion}

The main cause of spinal cord dysfunction in CS is compression, stretch or rotation of spinal cord secondary to the spinal deformity itself. Posterior column dysfunction in patients with CS who were are sensitive to vibration in the lower extremity compared with normal population has been demonstrated ${ }^{[6]}$. In clinical practice, spinal cord function in CS is routinely evaluated by radiographic tests and neurologic examination. MRI can detect the structural abnormalities of spinal cord that is not necessarily related to alteration of spinal cord function. Routine clinical examination can offer information on the neurologic symptoms, but it cannot serve as an accurate assessment of spinal cord function and the responsible level of spinal cord ${ }^{[7]}$.

SEPs are generally used to reflect posterior column pathways function. DSEPs are stimulated in the dermatomal area innervated by nerve roots, causing excitation from peripheral nerves up to the spinal cord and brainstem and crossed via the thalamus to the cortical sensory areas of the brain, and waveforms can be recorded on the scalp corresponding to the cortical sensory areas, and damage to the nerve roots can be reflected by changes in wave amplitude and latency, whereas SSEPs are elicited by stimulating the peripheral mixed nerves and placed on the patient's scalp Recording electrodes, which record bioelectrical signals with a locking time relationship to the stimulus, are used to reflect the integrity of the sensory conduction pathway. Therefore, DSEPs are more reflective of single nerve root functional traits than SSEPs. 
SSEPs recordings can help to determine the presence, severity, and prognosis of neurologic deficits, and the functional relevance of an anatomic lesion in spinal cord. However, SSEPs response of mixed nerves may not be useful in the evaluation of the physiologic status of a single root because mixed nerves enter the spinal cord from more than one level. SSEPs have been found only occasionally helpful, while they give many false negative results due to the low sensitivity of standard outcome metrics ${ }^{[8,9]}$. In this study, SSEPs abnormality rate in patients with neurologic symptoms was significantly lower than that in patients without neurologic symptoms. The result suggested the non-agreement between clinical neurologic examination and SSEPs findings.

DSEPs could objectively reflect the conducting function of any level of the spinal cord and their segmental specificity is expected to be more than those of SSEPs ${ }^{[10]}$. The abnormal rate of DSEPs is much higher than that of SSEPs. It is considered that DSEPs has high sensitivity in patients with CS. In practical work, the operation of DSEPs is simple, and multi-segmental and large-scale examination can be carried out according to the scope of the lesions. It can objectively reflect the conduction function of each nerve root. The SSEPs of thoracolumbar scoliosis is obtained by stimulation of the posterior tibial nerve, while the posterior tibial nerve is a mixed nerve of L4-S2, which is composed of more than three nerve roots. When a single nerve root is involved, electrical stimulation may cause multiple nerve roots to be excited at the same time, thus covering the abnormal conduction of the involved nerve roots and limited response segments, which affects the sensitivity of posterior tibial nerve SSEPs in electrophysiological diagnosis of scoliosis patients. The large-scale and multi-segmental advantages of DSEPs just make up for the shortcomings of SSEPs of the posterior tibial nerve ${ }^{[11,12]}$. In congenital scoliosis, there are many segments of spinal deformity, and the abnormal range of DSEPs is also large, with different manifestations. Multi-segmental DSEPs examination with the parietal vertebra as the center shows prolonged latency, decreased amplitude, poor waveform differentiation, or even disappeared.

The highest positive rate of each index in the classification of waveform abnormalities was found in the latency prolongation and latency interlateral difference(Table 2). Therefore, the DSEP of patients with unilateral symptoms should not be examined only on the affected side, but should be routinely examined bilaterally, and bilateral interlateral comparisons should be performed. The DSEP and SSEPs of patients with scoliosis with and without clinical symptoms were statistically analyzed, and 62 patients showed abnormal DSEPs, among which the abnormality rate of SSEPs was $20 \%$ in 10 patients with clinical symptoms and $44.2 \%$ in 52 patients without clinical symptoms. The abnormalities of DSEP and SSEPs in patients with scoliosis were not correlated with clinical symptoms. Clinically, this neurophysiological examination should be performed even if the patient is asymptomatic.

In this retrospective monocentric study, all 62 patients had abnormal waveforms of DSEPs, however, only 25 patients had abnormal waveforms of SSEPs, indicating that DSEPs were more sensitive than SSEPS in detecting posterior column dysfunction which is difficult to evaluate by routine clinical examination. 
The detection rate of MRI suggestive of spinal cord developmental malformations was $37.3 \%$, which was $79.6 \%$ of the detection rate of DSEPs abnormalities, with statistically significant differences. DSEPs can reflect different levels of spinal cord functional changes in patients with congenital scoliosis, providing evidence for the type of neurophysiological dysfunction in patients with congenital scoliosis, and can be used as an adjunctive diagnostic tool to MRI. The incidence of abnormal segments of DSEPs was $79.6 \%$ $(153 / 192)$ in patients with spinal cord developmental malformations and $57.9 \%(171 / 295)$ in patients without spinal cord developmental malformations(Table 4), suggesting that the abnormality rate of DSEPs with spinal cord developmental malformations was greater than that without spinal cord developmental malformations. The degree and extent of abnormal DSEPs were positively correlated with the degree of spinal cord developmental deformity, but not with clinical symptoms; regardless of whether patients with scoliosis are clinically symptomatic or not, DSEPs can be used as an objective indicator to assess the functional properties of the patient's nerve and spinal cord before conservative or surgical treatment, and can provide an objective basis for possible medical disputes after surgery.

\section{Conclusion}

In conclusion, compared with SSEPs, DSEPs are sensitive in detecting subtle posterior column dysfunction in patients with CS which are undetectable by radiographic and routine clinical examination. Intraspinal pathologies associated with CS give rise to the range of abnormal DSEPs. Preoperative DSEPS assessment is recommended as a baseline examination for intraoperative monitoring and to allow comparisons with the postoperative condition. DSEPs recordings are complementary to information obtained by routine clinical and radiological evaluation.

\section{Abbreviations}

SEPs: List of Abbreviations Somatosensory evoked potentials; DSEPs: Dermatomal somatosensory evoked potentials; CSEPs: Cortical somatosensory evoked potentials; CS: Congenital scoliosis; MRI: Magnetic resonance imaging.

\section{Declarations}

\section{Acknowledgements}

The clinical ethics committee of Xi'an Honghui Hospital generously supported the collection and analysis of these data. We acknowledge support by the Hubei Province Natural Science Foundation (No: 2020CFB551).

Author Contributions: ZZX: Investigation, Formal analysis, Data Curation, Writing - review \& editing, Visualization. WY: Investigation, Formal analysis, Data Curation, Writing - review \& editing, Visualization. LT: Investigation, Writing - review \& editing. YY: Formal analysis, Writing - original draft. LJF: 
Conceptualization, Supervision, Writing - review \& editing. All authors read and approved the published version of the manuscript.

Funding: This work was financially support by Hubei Province Natural Science Foundation (No: 2020CFB551).

\section{Ethics approval and consent to participate}

According to the Ethical Review of Biomedical Research Involving Humans issued by the National Health Committee of China, previously archived data, documents and records are exempt from ethical review if they do not involve personal privacy or commercial interests. This research project is a retrospective case analysis, which strictly adheres to the Declaration of Helsinki and was approved by the Biomedical research ethics committee of Hong Hui Hospital, Xi'an Jiaotong University. We confirm that we have read the Journal's position on the issues involved in ethical publishing and that this report complies with these guidelines.

\section{Consent for publication}

Not applicable.

\section{Availability of data and materials}

The data that support the findings of this study are available from Xi'an Honghui Hospital, but restrictions apply to the availability of these data, which were used under license for the current study, and so are not publicly available. Data are however available from the authors upon reasonable request and with permission of Xi'an Honghui Hospital.

\section{Competing interest}

The author(s) declared no potential conflicts of interest with respect to the research, authorship, and/or publication of this article.

\section{Author details}

${ }^{1}$ Department of Orthopaedics, Xi'an HongHui Hospital, Xi'an Jiaotong University, Xi'an, Shaanxi, China. ${ }^{2}$ Department of Orthopedics, Zhongnan Hospital of Wuhan University, Wuhan, Hubei, China. ${ }^{3}$ Department of Functional Examinantion , Xi'an HongHui Hospital, Xi'an Jiaotong University, Xi'an, Shaanxi, China.

\section{References}

1. Basu PS, Elsebaie H, Noordeen MH. Congenital spinal deformity: a comprehensive assessment at presentation. Spine. 2002; 20(27): 2255-9. 
2. Prahinski JR, Polly DW, McHale KA. Ellenbogen RG. Occult intraspinal anomalies in congenital scoliosis. J Pediatr Orthop, 2000; 20(1): 59-63.

3. Belmont PJ『Kuklo TR囚Taylor KF et al. Intraspinal anomalies associated with isolated congenital hemivertebra: The role of routine magnetic resonance imaging. J Bone Joint Surg Am. 2004; 86(6): 1704-10.

4. Sub SW, Sarwark JF, Vora A et al. Evaluating congenital spine deformities for intraspinal anomalies with magnetic resonance imaging. J Pediatr Orthop. 2001; 21:525-531.

5. Aminoff MJ. The use of somatosensory evoked potentials in the evaluation of the central nervous system. Neurol Clin. 1988; 6(4): 809-823.

6. Whitecloud TS, Brinker MR, Barrack RL et al. Vibratory response in congenital scoliosis. J Pediatr Orthop. 1989;9(4):422-6.

7. Greenberg RP, Ducker TB. Evoked potentials in clinical neurosciences. J Neurosurg. 1982; 56(1):118.

8. Hu Y, Ding Y, Ruan D et al. Prognostic value of somatosensory-evoked potentials in the surgical management of cervical spondylotic myelopathy. Spine 2008;33(10):305-310.

9. Plastaras CT. Electrodiagnostic challenges in the evaluation of lumbar spinal stenosis. Phys Med Rehabil Clin N Am. 2003; 14(1):57-69.

10. Sohn SY, Seo JH, Min Y et al. Changes in dermatomal somatosensory evoked potentials according to stimulation intensity and severity of carpal tunnel syndrome. J Korean Neurosurg Soc. 2012; 51(5):286-291.

11. Slimp JC, Rubner DE, Snowden ML, et al. Dermatomal somatosensory evoked potentials:cervical, thoracic, and lumbosacral levels. Electroencephalogr Clin Neurophysiol. 1992;84:55-70.

12. Essa ZM, Al-Hashimi AF, Nema IS. Dermatomal Versus Mixed Somatosensory Evoked Potentials in the Diagnosis of Lumbosacral Spinal Canal Stenosis. J Clin Neurophysiol. 2018; 35(5):388-398.

13. Storm SA, Kraft GH. The clinical use of dermatomal somatosensory evoked potentials in lumbosacral spinal stenosis. Phys Med Rehabil Clin N Am. 2004; 15:107-115. 